\title{
Research on the teaching of programming language based on Computational Thinking
}

\author{
Lu Ying \\ School of Computer Science and Engineering \\ Xi'an Technological University, \\ Xi'an, China \\ e-mail: luyingkk@sina.com
}

\author{
Liu Pingping \\ School of Computer Science and Engineering \\ Xi'an Technological University, \\ Xi'an, China \\ e-mail: liupingping@sina.com
}

\begin{abstract}
This paper is about studying and exploring how to Integrate Computing Thinking into Program Design Courses. First, this paper will provide theoretical analysis of computing thinking. Second, it will analyze existing problems of program design course with traditional teaching method. Third, it will propose ideas of integrating computing thinking into Program Design Courses. Last, the results of new ideas will be analyzed and reviewed through teaching practices.
\end{abstract}

Keywords-Computational Thinking; Program Design; Language; Teaching Process

\section{INTRODUCTION}

Modern computer science education, almost all education institutes have fundamental courses of computer program design. These courses will use programming languages to introduce the basic methods of program design, so that students can understand the concepts and methods of using computers as tools to solve problems. But after many years of instructing and observation, it realized a lot of students with above average grades still cannot solve the realistic problems in their specific professional areas after these courses. Explore the root causes of this problem, it's mainly because students are still missing induction and fostering of effective computing thinking. In order to avoid the phenomenon of "high score and low abilities", how to cultivate students' computing thinking ability in a scientific way has become a key concern in instructing program design courses nowadays.

\section{THE THEORY OF COMPUTING THINKING}

Computing thinking is always contained in the thought process of human problem-solving, but it has not been emphasized and brought to attention. In 2006, zhouyizhen, professor of computer science at Carnegie Mellon university, systematically elaborated and defined the computational thinking [1]. Professor Zhou argues that computing thinking is a series of thinking activity covering the breadth of computer science, including using the basic concepts of computer science to solve problems, system designing and the understanding of human behavior. It learned the general scientific thinking methods, including the general mathematics thinking method for problem solving, general engineering thinking methods for designing and evaluating complex systems in the practical world and the understanding of the complexity, intelligence, psychology, human behavior. It covers a range of thinking activities including computer science [2].

Therefore, computing thinking is not only referring to the application of thinking in the program design, machine programming, but a human behavior of using the machine that can calculate and the basic concepts to design systems and solve problems[3].

Human's computing thinking behaviors are unconscious. Therefore, the key of computer program design teaching is to train this unconscious thought habit into a conscious computing thinking. It makes students actively use computing thinking to solve problems in any case. Thus, the 
fundamental goal of computing thinking can be achieved, better serving the specific professional area of each student.

\section{Classes INTEGRATED WITH COMPUTING THINKING}

\section{A. Traditional Classroom Teaching}

The keys of program design course teaching is the kind of teaching model adopted, which integrating computing thinking into program design concepts and methods in order to Improve students' independent thinking and exploration ability[4-5]. We have advocated that the teaching process should focus on the guidance of "thinking" and "methods". Don't over stick to programming syntax. Introducing different Algorithmic Mechanisms to solve the same problem. However, there are still some deep-rooted problems in the course of classroom teaching.

1) The classroom teaching pays much attention to the explanation of the form of language expression, but missing programming teaching that using thinking method as the core

The instructors prefer to demonstrate the smart ways of using functions and syntax, but not properly relating with algorithm thoughts. Therefore, they cannot effectively teach students to analyze and solve problems. As a result, students' programming skills and problem-solving skill are not thoroughly trained, so that instructors cannot guide students to conduct and accomplish any professional research.

2) In traditional classroom teaching, communication between instructors and students is missing. With traditional learning modal, compulsive memorizing, mechanical imitating and repetitive practicing make students lose interests of programming technologies, which is not good for cultivating students' thinking ability and solving practical problems

What is the most effective way to teach students? We have to realize that computers are just carriers of thought and calculations. Computer Science is the same as Math, Physics and other natural sciences, we need to learn the thoughts of how to solve problems effectively. Therefore, the teaching process must pay attention to the thinking method of program design, and consciously use computing thinking to analyze and solve problems. In this way, we can lay a good foundation for our future professional study.

\section{B. Computing Thinking Teaching}

In programming design teaching, analysis and design of algorithms mostly embody the computing thinking. Algorithm is the methods and steps of solving problems, it is a finite set of rules. We used computing thinking to train students, and then taught them how to write codes and get results.

\section{1) Create problem scenarios}

In this program design class, instructor gave a clear task, building Guessing Number Game. (Figure 1):

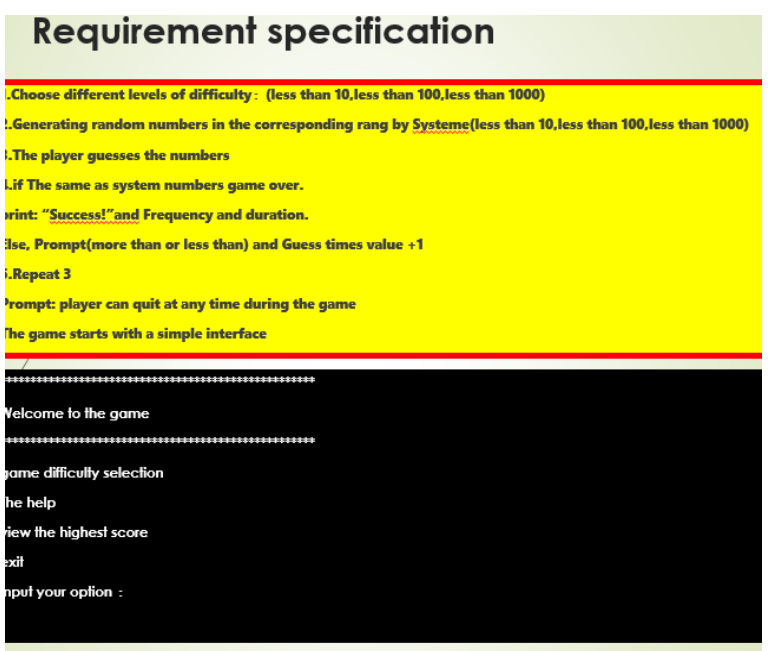

Figure 1. Create problem scenarios.

Instructor demonstrated the UI and functions while the game is running at beginning of the class. (Figure 2)

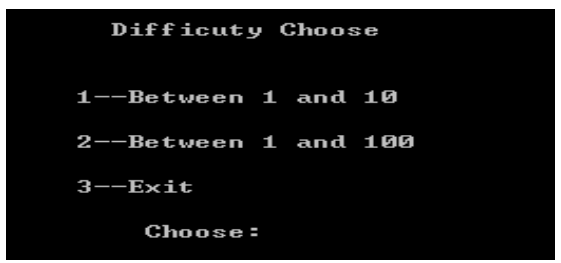

Figure 2. Game UI

The topic has remarkable thinking characteristics and students are very interested. The instructor guided students to think about solutions of the task in a whole, which can foster thinking consciousness of solving problems. 
Because the topic was game nature, lively and interesting, students had positive intentions to solve the problem since the beginning of the class. Instructors should play a leading role at the time, using various methods of computing thinking to perform heuristic teaching, and guide the students in a positive way and to help them in time. During the semester, the main line of teaching is clear, students became proactive and voluntarily learned programming.

\section{2) Problem analysis}

The instructor divided students into groups and discussed the topic between groups and within groups. Each group was led by a better student as a group lead. A series of speculations, discussions, learning and communication have been taken place in a good environment, which enables students to help each other and achieve mutual improvement. Instructor should provide guidance while students are overwhelmed by attempting to find out solutions. For instance, providing hints for generating a random number that is small than 10. By demonstrating the diversity of algorithms to transfuse computing thinking, which can help cultivate students' computing thinking skills.

\section{3) Propose algorithm and solve the problem}

After the analysis of the problem, the specific solution or implementation steps are given to carry out the experiment. At this time, the instructor needs to evaluate the solution, instruct the student to use the coding environment to track and debug and find logic errors. For example, in this question, 4 numbers need to do circular comparison to find out which numbers are correct and at the right positions. This problem involves the circular comparison of arrays, so students may make mistakes easily. Instructor can help students to setup breakpoints in VC debugging environment and use step tracking to monitor changes of the corresponding variables and debug.

\section{4) Outcome presentation}

The each group, led by group lead, organized a presentation or workshop to share their suggestions, plans and the process of solving the problems to other teams, which can achieve mutual improvement. Instructors should give proper affirmation and comments at this time, and guide students to solve practical problems.

\section{5) Evaluation and summarizing}

The evaluation information is an effective tool for monitoring students' abilities of handling problems, adjusting teaching design, and further students' self-reflection. During the number guessing game in the previous phrase, students had gone through the process from being overwhelmed to solving the problems.

\section{RESUlt REVIEWING}

\section{A. Experimental Objects Selection}

Experimental objects are students from 110701-704 and 12701-705 classes, who took Fundamental Computer Program Design course. Classes from 2 different grades were in the same major, they have similar computer skills. 120701-705 is selected as experimental class and $110701-704$ is selected as control class.

\section{B. Evaluation method}

Experiment process is as follow:

First, experimental class used computing thinking modal, used the 5-steps scheme to design the teaching process of Fundamental Computer Program Design course. Second, Control class used the traditional teaching process, instructor talking and demonstrating and students just listening and exercising as the main process. Finally, evaluated the result of teaching reform based on the result of the teaching evaluation filling form, questionnaires, test results and statistics:

1) The number of students interested in learning from the experimental class was significantly higher than that of the control class

Delivered 90 questionnaires and collected 71 effective responses in experimental class. Delivered 72 questionnaires and collected 56 effective responses. Statistical analysis of the valid responses is shown in the table 1 . 
TABLE I. COMPARISON OF LEARNING INTERESTS BETWEEN EXPERIMENTAL AND CONTROL CLASSES

\begin{tabular}{|c|c|c|c|}
\hline $\begin{array}{c}\text { Research } \\
\text { Question }\end{array}$ & Options & $\begin{array}{c}\text { Experimental } \\
\text { Class }\end{array}$ & $\begin{array}{c}\text { Control } \\
\text { Class }\end{array}$ \\
\hline Interested & Very & $82 \%$ & $40 \%$ \\
in & interested & $13 \%$ & $27 \%$ \\
Learning & Interested & $5 \%$ & $33 \%$ \\
& Not Interested & & \\
\hline
\end{tabular}

From Table 1, students from experimental class has higher interests of learning than that of control class. This indicates adopting computing thinking teaching scheme can significantly improve the learning interests of students.

2) Llearning initiatives of students in the experimental class is better than control class

TABLE II. COMPARISON OF LEARNING INITIATIVE BETWEEN EXPERIMENTAL CLASS AND CONTROL CLASS

\begin{tabular}{|c|c|c|c|}
\hline $\begin{array}{c}\text { Research } \\
\text { Question }\end{array}$ & Options & $\begin{array}{c}\text { Experimen } \\
\text { tal Class }\end{array}$ & $\begin{array}{c}\text { Control } \\
\text { Class }\end{array}$ \\
\hline Preparation & $\begin{array}{c}\text { Always } \\
\text { Sometimes } \\
\text { Never }\end{array}$ & $\begin{array}{c}71 \% \\
18 \%\end{array}$ & $\begin{array}{c}28 \% \\
11 \%\end{array}$ \\
& Always & $73 \%$ & $24 \%$ \\
\hline Review & Sometimes & $17 \%$ & $43 \%$ \\
& Never & $10 \%$ & $33 \%$ \\
\hline Ask questions & Always & $66 \%$ & $25 \%$ \\
on the class & Sometimes & $27 \%$ & $56 \%$ \\
& Never & $7 \%$ & $19 \%$ \\
\hline
\end{tabular}

From table 2, the students' attitudes of preparing for classes, reviewing after classes and asking questions on class in the experimental class are significantly better comparing to control class. The class with computing thinking teaching scheme is obviously better than the control class for learning voluntary and the active thinking about the problem.
From the above, the integrating teaching scheme with computing thinking can effectively arousing the students interest and motivate them to study conscientiously.

\section{CONCLUSION}

The classes of computing thinking is to train students to use computing thinking methods to discover, analyze, solve and summarize problems. During the teaching practice in future, it is necessary to frequently summarize and improve teaching methods and teaching strategies, main concerns are: how to develop a teaching outline that is suitable for students' computing thinking cultivation and development; how to select appropriate the topics and scenarios for computing thinking cultivation; how to refine the tasks of cultivating computing thinking; how to establish a diversified teaching quality evaluation system, and other relevant problems.

\section{ACKNOWLEDGMENT}

School reform project: xi'an university of technology, 2016 university computer foundation core curriculum construction.

\section{REFERENCES}

[1] Zhou Yi-zhen. Computational Thinking. CCCF, 2007.

[2] John Ziman.Real Science-What it is and What it is means [M].Shang Hai: Shanghai technology education press, 2008.

[3] Liu Yongjuan, Lao Yi. Reform and Practice of University Computer Teaching Based on the Computational Thinking. 2015, 12:16-18.

[4] Jeannette M. Wing. Computational Thinking [J]. Communicationsof ACM, 2006, 49(3): 33-35.

[5] He qing-ming,Lu han-quan,Feng bo-qing. The core task of basic computer teaching is to cultivate the ability of Computational Thinking [J]. China University Teaching. 2010, 9:5-9. 